\title{
Centralidade de vínculos familiares na experiência de mulheres de meia-idade*
}

\section{Centrality of family bonds in the experience of middle-aged women \\ La centralidad de los vínculos familiares en la experiencia de las mujeres de mediana edad}

Como citar este artigo:

Rodrigues LSA, Coelho EAC, Aparício EC, Silva DMGV, Almeida MS, Cabral LS. Centrality of family bonds in the experience of middle-aged women. Rev Esc Enferm USP. 2021;55:e03734. https://doi.org/10.1590/S1980-220X2020020503734

\section{Larissa Silva de Abreu Rodrigues ${ }^{1}$ \\ Edméia de Almeida Cardoso Coelho ${ }^{2}$ \\ Elena Casado Aparício ${ }^{3}$ \\ Denise Maria Guerreiro Vieira da Silva $^{4}$ \\ Mariza Silva Almeida² \\ Letícia da Silva Cabral²}

* Extraído da tese: "Demandas de saúde na experiência de mulheres de meia idade", Programa de Pós-Graduação em

Enfermagem, Escola de Enfermagem,

Universidade Federal da Bahia, 2018.

${ }^{1}$ Universidade do Estado da Bahia, Departamento de Educação, Guanambi, BA, Brasil.

${ }^{2}$ Universidade Federal da Bahia, Programa de Pós-Graduação em Enfermagem e Saúde, Salvador, BA, Brasil.

${ }^{3}$ Universidad Complutense de Madrid, Madri, Espanha.

${ }^{4}$ Universidade Federal de Santa Catarina, Florianópolis, SC, Brasil.

\section{ABSTRACT}

Objective: To analyze meanings attributed to middle-aged women from their experience in their family relationships. Method: Qualitative study of the Convergent Care Research method. Gender was used as an analytical category, developed with a total of thirteen middle-aged women from the coverage area of the Family Health Strategy program in a city in the southwest of Bahia state, through reflection workshops and interviews. Data were analyzed using discourse analysis. Results: They express the affective relationship with children and grandchildren as the greatest highlight of middle age in overlap with the relationship with partners and other bonds, which makes their uniqueness and identification of demands for health care unfeasible. Conclusion: Female middle-aged are marked by conceptions of femininity that emerge from their condition as a womanmother, from her complete donation. The research points to an urgent need to add gender as a reference for the care of middle-aged women, in order to consider the biopsychic and social interlaces in their life experience and that outline demands for care.

\section{DESCRIPTORS}

Middle Aged; Women's Health; Family Relations; Gender and Health; Integrality in Health. 


\section{INTRODUÇÃO}

A meia-idade é compreendida como período da vida dentro da denominada idade adulta, inserida no processo de envelhecimento ${ }^{(1)}$. Diversos estudos a delimitam como período dos 45 aos 59 anos $^{(2-5)}$. A vivência da mulher de meia-idade configura-se, em parte, pelo modo como cada cultura concebe o processo de envelhecimento e os papéis sociais da mulher. Assim, é necessário romper com discursos que favorecem o estigma associado à meia-idade feminina e, ao mesmo tempo, abrir possibilidades para compreensão da pluralidade de ser mulher de meia-idade, tendo em vista mudanças corporais, familiares, laborais e sociais, histórica e socialmente situadas, que extrapolam a ocorrência da menopausa ou o ninho vazio, causado pela saída dos/as filhos/s de casa.

Nesse período, ocorrem transformações no âmbito da vida, do trabalho e das relações familiares como viuvez, divórcio, saída dos/as filhos/as de casa e/ou chegada de netas/os. Além disso, muitas mulheres vêm casando e tendo filhos/as "mais tardiamente", delineando novas configurações e arranjos: mulheres de meia-idade com filhos/as, crianças e adolescentes em casa, podendo ainda ter como responsabilidade o cuidado do pai e da mãe idosos/as, o que pode afetar a vivência desse período de transição( ${ }^{()}$. Apesar da complexidade das questões biopsicossociais e culturais que permeiam a meia-idade feminina, as ações de saúde direcionadas às mulheres de meia-idade no Brasil e em outros países têm sido insuficientes, mesmo no contexto da atenção primária ${ }^{(7-8)}$.

A Política Nacional de Atenção Integral à Saúde da Mulher (PNAISM) aborda a saúde da mulher na meia-idade como climatério, apresentando plano de ação para implantar e implementar a atenção para esse grupo populacional em nível nacional ${ }^{(9-10)}$. Estudo realizado em uma Unidade de Saúde da Família na cidade de São Paulo-SP sinaliza que não há uma demanda organizada para o desenvolvimento de ações junto a mulheres, sendo que os atendimentos existentes ocorrem por demanda espontânea ou são orientados por ações protocolares, tais como os programas de prevenção de cânceres de colo de útero e mama, de controle da hipertensão arterial e do diabetes, que parecem enfocar as doenças e fragmentar o cuidado ${ }^{(11)}$.

Em contextos de medicalização da saúde, as questões de gênero são quase sempre ausentes do serviço de saúde e também das demandas mais valorizadas pelas usuárias, não por sua inexistência, mas por aculturação para a medicalização. Nessa perspectiva, faz-se necessária visão crítica sobre as implicações de gênero no âmbito da saúde e sobre as contradições e limitações da lógica biomédica que obstaculizam essa percepção $0^{(12)}$.

Assim, considerando necessário agregar conhecimento que supere a visão estritamente médica da meia-idade, buscando levantar subsídios para propostas de cuidado a essas mulheres, temos o seguinte objetivo: analisar sentidos atribuídos à meia-idade a partir da experiência de mulheres que a vivenciam em suas relações familiares.

\section{METÓDO}

\section{Desenho do estudo}

Este estudo caracteeriza-se como qualitativo do tipo Pesquisa Convergente Assistencial (PCA), consistindo em método de pesquisa em que há o compromisso com a construção de conhecimento e a justaposição aos processos e práticas do cuidar ${ }^{(13)}$. Trata-se de recorte de pesquisa maior, intitulada Demandas de saúde da experiência de mulheres de meia-idade, que envolveu profissionais de saúde e mulheres de meia-idade. Neste artigo, apresentamos os resultados referentes à categoria empírica intitulada Centralidade dos vínculos familiares na meia-idade, composta em sua totalidade por discursos de mulheres de meia-idade.

Gênero foi utilizada como categoria analítica. Constitui construto sócio-histórico-cultural, que delimita papéis sociais hierarquizados para mulheres e homens. Como categoria de análise, favorece o reconhecimento de assimetrias de caráter relacional arroladas ao feminino e ao masculino e suas implicações no cotidiano das relações e na configuração das demandas de saúde das mulheres ${ }^{(14)}$.

\section{CRITÉRIOS DE SELEÇÃo}

Foram critérios de inclusão estar na faixa etária de 45 a 59 anos e ser usuária de uma Estratégia Saúde da Família de um município do sudoeste baiano (ESF). Estabeleceu-se como critério de exclusão o seguinte fator: estar grávida. Definimos o quantitativo de duas ou três mulheres por microárea, o que totalizou dezesseis convites feitos pela pesquisadora por meio de visita domiciliar, acompanhada pela agente comunitária da microárea, agendando-se o primeiro encontro. Dias e horários dos encontros subsequentes foram acordados ao final de cada oficina.

\section{PopulaÇão}

Dez mulheres compareceram na primeira oficina, uma compareceu somente à segunda e duas foram inseridas posteriormente, participando dos terceiro e quarto encontros. Assim, treze mulheres de meia-idade de uma unidade de saúde da família em município do sudoeste baiano, onde a pesquisadora desenvolve atividades regulares na condição de docente universitária, compõem a população desta pesquisa.

\section{Produção do material empírico}

A produção do material empírico ocorreu mediante a realização de duas oficinas de reflexão e entrevistas nos meses de maio e junho de 2017. As oficinas de reflexão oferecem espaço de discussão e intervenção educativa sobre questões ligadas ao cotidiano das mulheres e sobre as relações de gênero, possibilitando horizontalidade de poder ${ }^{(15)}$. Cada oficina foi realizada pela pesquisadora com duas ou três colaboradoras, sendo iniciada após preenchimento de formulário de identificação e de dados socioeconômicos. A operacionalização ocorreu seguindo as etapas: Apresentação/Descontração; desenvolvimento do tema; 
socialização das Experiências; síntese, realizada pela coordenadora; e avaliação, feita pelo grupo ${ }^{(16)}$.

A primeira oficina buscou sensibilizar as mulheres para o cuidado na perspectiva da valorização de aspectos subjetivos, problematizar a realidade com escuta sensível, acolhimento e identificação de demandas, enquanto a segunda buscou o olhar das mulheres sobre demandas levantadas. O tempo médio dos encontros foi de três horas, com lanche no intervalo. O processo foi fotografado, as falas gravadas e transcritas na íntegra e as observações registradas em diário de campo. As falas foram organizadas na forma de narrativa e examinadas no intuito de identificar aspectos relevantes direcionados aos objetivos da pesquisa, o que gerou uma síntese.

Uma vez transcritas as falas e examinadas segundo os objetivos da pesquisa, foram identificadas cinco mulheres em que havia necessidade de aprofundar temas de seu discurso por meio da entrevista, por maior necessidade de escuta, considerando as demandas apresentadas. Observamos, para além dos discursos, silêncios e expressões de inquietude/ansiedade. Essas participantes tinham demandas relacionadas a envolvimento de filhos com drogas, violência doméstica, sobrecarga com trabalhos domésticos, filhos/as que ainda demandam suporte financeiro e cuidado, ansiedade e dificuldades para dormir. Assim, cinco mulheres foram selecionadas e convidadas a participar da entrevista, sendo acordados data e horário para sua realização dessa. Apenas uma entrevista foi realizada no domicílio da participante, por sua escolha.

Oficinas de reflexão e entrevistas, além de estratégias metodológicas para produção do material empírico, possibilitaram a convergência pesquisa-cuidado, atendendo aos princípios da PCA. As oficinas favoreceram troca de experiências e abordagem reflexiva sobre a meia-idade sob perspectiva problematizadora. $\mathrm{Na}$ interação, as participantes resgataram emoções, experiências e trocaram conhecimentos e estratégias para lidar com suas demandas. Nas entrevistas, as mulheres mostraram estar em uma relação de confiança com a entrevistadora e fizeram relatos da intimidade de sua vida que, ainda que não fossem necessários como dados empíricos para pesquisa, se mostraram importantes para elas, pela necessidade de escuta e acolhimento.

\section{ANÁLISE E TRATAMENTO DOS DADOS}

A análise dos dados foi realizada por meio da técnica de análise de discurso segundo Fiorin, para a qual o discurso é uma posição social, cuja formação ideológica é materializada na linguagem ${ }^{(17)}$.Cumprimos as seguintes etapas: 1) Leitura exaustiva de todo o texto para identificação de elementos semânticos concretos (figuras) e abstratos (temas) que conduzem a um mesmo plano de significação; 2) Agrupamento dos dados de acordo com os elementos significativos que conformam um mesmo plano de significado; 3) Depreensão dos temas centrais; e 4) Formação das categorias empíricas ${ }^{(18)}$.

\section{Aspectos Éticos}

A pesquisa foi conduzida de acordo com os padrões éticos exigidos na Resolução n ${ }^{\circ}$ 466/2012 do Conselho Nacional de Saúde, sendo aprovada pelo Comitê de Ética em Pesquisa da Universidade do Estado da Bahia (UNEB) no ano de 2017, sob parecer de número 2.063.533. Para assegurar o anonimato, as participantes foram identificadas com a letra $\mathrm{P}$, seguida de algarismo arábico. As abreviações correspondentes à técnica que possibilitou o registro da fala das mulheres, oficinas (OF) e entrevista (E) constam no final de cada fala.

\section{RESULTADOS}

Participaram do estudo mulheres na faixa etária de 45 a 58 anos. Cinco mulheres eram analfabetas, quatro tinham ensino fundamental completo ou incompleto, três tinham ensino médio completo e uma finalizou ensino superior. Dez se autodeclararam pardas, duas negras e uma se autodeclarou branca. Sete mulheres estavam casadas ou em união estável, cinco divorciadas e separadas e uma estava solteira. Dez informaram ser católicas e três informaram ser evangélicas.

Quanto às ocupações, informaram ser vendedora de verduras, lavadeira de roupa, dona de casa (cinco), boleira/confeiteira, costureira, técnica de enfermagem, doméstica/diarista (duas), uma se encontrava aposentada e outra recebendo auxílio doença. Duas eram recebedoras do benefício social do Programa Bolsa Família. Quanto à renda familiar, variou de menos que um salário mínimo a três salários mínimos.

A categoria empírica central, que dá título ao artigo, é analisada a partir das subcategorias empíricas que seguem:

\section{PotÊNCIA DA MATERNIDADE COMO MARCA DA MEIA=IDADE}

Filhos/as e netos/as apresentam centralidade na vida das mulheres que participaram da pesquisa e foram considerados/as as melhores marcas da meia-idade, representadas como tudo na vida, amor, paixão, alegria, motivo de gratidão a Deus, de orgulho e de completa doação, conforme lê-se nos depoimentos que seguem:

Meus filhos são tudo para mim. Todos eles na hora que eu adoeço está do meu lado. (...) Eu amo meus filhos. Eu sou apaixonada pelos meus filhos (P4, 46 anos, OF).

O que marca minha vida é meus filhos, que eu tenho orgulho de todos os quatro filhos que eu tenho e dos meus quatro netos (P6, 51 anos, OF).

As mulheres falam da maternidade como potência e remetem-se, em alguns momentos, à plenitude por ter parido, ter criado e ver filhos/as construindo independência, formando novas famílias e iniciando nova geração:

Minha filha é tudo na minha vida. Tudo que eu faço é para minha filha (...) Hoje em dia, está aí, está lá em São Paulo fazendo a faculdade dela. Ela fez o técnico de enfermagem. Falou que queria uma coisa a mais, está lá fazendo engenharia (P1, 49 anos, OF).

As flores que eu apresento na minha idade de hoje é meus filhos, meus netos que eu sempre pedi a Deus para me dá saúde para alcançar (P12, 54 anos, OF).

A única mulher que não foi mãe considera ser possível ser feliz sem filhos/as, mas é questionada por uma das participantes, conforme diálogo que segue: 
A mulher que não tem filho, ela não tem alegria na vida. (P4, 46 anos, OF).

Não tenho filhos, mas sou alegre, feliz (P8, 45 anos, OF).

Sim, mas fica um vazio. Não fica?! Fica um vazio. Eu nunca vi uma mulher que não teve filho não ter vontade $(\mathrm{P} 4$, 46 anos, OF).

Ao afirmar a não realização do sonho de ser mãe, buscando no cuidado de sobrinhos exercer a maternidade, conforme lê-se a seguir, a participante P8 expressa ambivalência na direção de existir esse vazio, embora outras realizações se destaquem:

Se realizar profissionalmente, ter a familia sempre por perto, ter um trabalho, ser mãe (...) Consegui com muito sacrifício fazer uma faculdade e ter uma profissão (...) Não consegui me realizar como mãe que era o meu sonho ser mãe também, mas não tenho nenhum problema com isso. Eu cuido muito dos meus sobrinhos como se fosse meus filhos (P8, 45 anos, OF).

A independência de filhos/as tem limitação em contextos sociais e econômicos desfavoráveis. $\mathrm{Na}$ realidade de algumas mulheres do estudo, filhos/as continuam demandando suporte financeiro e netos/as demandam cuidado:

Meus filhos eu ainda estou criando até hoje. Acabou de criar os filhos, vêm os netos dentro de casa. Então, fica a mesma coisa. Até hoje eu tô criando (P13, 52 anos, OF).

Eu tenho um filho que é dependente químico. Não me agride, mas eu ajudo a mulher dele mais os meninos. Quando ele não tá com a esposa, ele está lá em casa (P10, 52 anos, E).

Uma das participantes, ao se referir às razões pelas quais mulheres de meia-idade cuidam de netos/as, reconduzindo assim o papel materno, afirma:

A vida, você continua como se tivesse começando tudo de novo, parindo. Por isso que não tem tempo pra se cuidar. Que depois que vem os filhos vêm os netos (...) Tudo dentro de casa (...) (P8, 45 anos, OF).

O envolvimento de filhos com drogas faz com que, na meia-idade, preocupação, insegurança e medo constituam demandas de mulheres em face de problemas, cuja superação extrapola a condição de mães, como mostram falas a seguir:

Minha preocupação é meu filho mesmo (...) Ele usa maconba. Eu tenho medo porque eu já perdi um filho pro mundo das drogas também (...) vieram e mataram ele. Ai, eu tenho medo desse também porque o que eu vejo do outro, eu tô vendo nesse (P9, 48 anos, $\mathrm{E})$.

O que eu tenho mais é muita preocupação com o menino mais novo. Ele vivia no mundo desse povo das drogas (...) Voltou mexendo de novo com droga (P7, 50 anos, E).

\section{MEIA-IDADE COMO ESPAÇO DE IMPRIMIR SENTIDOS A EXPERIÊNCIAS COM PARCEIROS}

As participantes deste estudo resgataram suas experiências com foco também na relação com o parceiro, destacando-a como uma relação contratual, de provisão e proteção familiar, sem evidenciar questões mais íntimas, relacionadas ao amor romântico e à sexualidade.
Algumas referem violência doméstica como uma marca que se mantém na meia-idade, estando submetidas sob o argumento de filhos/as ainda dependentes, em contexto socioeconômico desfavorável:

Mas no meu caso é porque eu ainda tenho dois filhos pequeno. (...) Tem dia que ele [o marido] bebe que fala de mim que vai me matar. (...) Agora, se não fosse minha menina que tem problema, eu já tinha largado ele. Porque os filhos segura um pouco (P4, 46 anos, OF).

(...) Eu conheço muitas que desabafa comigo: "Só tô vivendo com esse homem dentro de casa por causa dos filhos"; "Se não fosse os filhos, eu já tinha largado"; "Ele fala que tenho que sair de casa porque a casa é dele" (P1, 49 anos, $\mathrm{OF})$.

Em simultaneidade à violência doméstica que afeta o bem-estar das mulheres, há situações em que parceiros desempregados e etilistas, ao realizar trabalhos eventuais, ignoram as responsabilidades com a provisão familiar:

Quando ele [marido] tá bêbedo, eu não durmo não. Eu fico com medo de dormir e ele me fazer alguma coisa (...) O que mais me incomoda hoje é ele ficar dentro de cas a sem arrumar um serviço. Isso é ruim demais (P4, 46 anos, $\mathrm{E})$.

$\mathrm{Na}$ experiência de mulheres, há também ruptura do casamento após filhos/as crescidos/as estabelecerem reestruturação da família nuclear em novo relacionamento. Esse novo vínculo é expresso como necessidade de proteção, segurança da provisão familiar, relações de respeito que atendem a uma demanda de família sem os conflitos da violência, em parceria financeira, permitindo uma melhora na condição de vida. Todavia, é demonstrado distanciamento afetivo sob referências do amor romântico, referido pela mulher como fruto de um acordo:

Eu conheci esse moço (...) ele não é estúpido comigo, não é bruto, não é ignorante. Dá bem com meus filhos (...). Mas é uma pessoa que eu tenho e nem sei porquê. Porque não tem mais aquele, o grande amor mesmo não tem (...) Tem aquele parceiro assim porque ó chega fim de semana, ele me dá $R \$ 100,00$ para fazer feira de carne, de verdura. Faz uma feira de cereais (...) Tipo assim, um sustento que eu tenho quando eu tô parada (P11, 58 anos, E).

Filhos/as crescidos/as abrem caminhos para mulheres libertarem-se de relacionamentos violentos, sendo essa condição também uma marca da meia-idade para as mulheres deste estudo:

Meu marido era muito ruim. Fiquei aguentando para criar os filhos. Depois eles cresceram, hoje eu tô livre dele. Vivo com meus filhos hoje e só tem harmonia (P5, 56 anos, $\mathrm{OF}$ ).

Nos depoimentos que seguem, diante de insatisfações acumuladas na relação conjugal, algumas mulheres mostram-se resignadas, sem vislumbre de mudana da realidade, não reconhecendo a meia-idade como um período em que a vida pode ser ressignificada e redirecionada. Blindam a maternidade, mas a experiência do casamento tem uma avaliação negativa. Assim, conferem às gerações atuais a condição para realizações sob novos valores, as quais ficam para elas no plano desejo:

Tá com trinta anos que eu casei. Se eu tivesse a experiência que eu tenho hoje, eu jamais casaria. Jamais. (...) Eu teria filhos, mas não casaria ( $\mathrm{P} 4,46$ anos, $\mathrm{OF})$. 
Se fosse meu tempo agora, eu não casaria. Eu fazia uma boa faculdade. Tinha um filho independente. E não queria homem na minha vida (P1, 49 anos, $\mathrm{OF})$.

\section{CuIDAdos DO/A OUTRO/A EM SOBREPOSIÇÃO AO CUIDADO DE SI PRÓPRIA}

Algumas mulheres, ao se referirem ao cuidado de si própria, atribuem a filhos/as um olhar sobre si vinculado à imagem de velha e sem os requisitos para ser admirada, sendo, por isso, desnecessário o cuidado da autoimagem e da autoestima. Assim, o tempo vivido é representado como destituinte da condição de mulher com corpo que expressa sexualidade/sensualidade:

Às vezes, até os filhos se é de dar apoio pra gente arrumar, pra gente andar mais bonita, pra gente sair, não... Faz é falar assim: "Por quê você quer isso?"; "Você já tá véia"; "Pra quê comprar roupa?"; "Pra quê ir em salão?"; "Pra quê tudo isso?" (P5, 56 anos, OF).

Essa posição social coexiste com outra em que filhos/as estimulam a mãe ao cuidado do corpo e da aparência sob o referencial da juventude, na perspectiva de distanciar sinais de envelhecimento, ao mesmo tempo em que a valoriza. No entanto, o sentido do envelhecimento se mantém negativo, como algo a ser evitado:

Os meus não. Eu falo "oh filho cê que acha? Eu não vou pintar meu cabelo mais não... vou deixar meu cabelo ficar branco..." Então, ele falou: "então cê tá doida... pra quê cê quer esse cabelo branco?!... tem que pintar pra ficar mais jovem e ir no salão para dar um check up no cabelo" e ainda me dá o dinheiro pra mim ir (...) (P6, 51 anos, OF).

É igual à minha. A minha, quando chega ai, ela me leva pro salão para eu fazer sobrancelha, dá relaxamento no cabelo... Ela já ligou pra mim e falou "mainha, já estou levando o relaxamento do seu cabelo"(...) quer que eu ando jovem do jeitim dela (P1, 49 anos, OF).

Algumas participantes revelam em seus discursos a forte incorporação do papel de reprodutora e da maternidade como suficiência para objetivos de vida. Sem projetos próprios como mulher, restringem sua existência à função materna, tendo filhos/as e netos/as como definidores de seu percurso:

Eu preocupava comigo quando minha filha era pequena. Agora ela está sobre si. Eu tinha medo de morrer e ela ficar pequena (...) mas agora ela já tá criada, tem 23 anos ( $\mathrm{P} 1,49$ anos, OF).

Eu só me preocupo com meus netos que tá pequeno ainda. Precisam de toda a atenção, eu não (P10, 52 anos, OF).

Duas participantes destacam-se ao serem enfáticas quanto à sua expectativa em relação à vida, remontando à ideia do ciclo biológico: nascer, reproduzir e morrer. Para essas, a meia-idade revela-se como possibilidade de encerramento de ciclo da vida:

Eu já vivi muito (...) Me preocupo com meus filhos, meus netos (...). Comigo eu não me preocupo não (P4, 46 anos, OF).
Qualquer coisa que acontecer comigo, eи não preocupo comigo (...) Eu já tô preparada pra isso (P1, 49 anos, OF).

As mulheres que afirmaram preocupar-se consigo e buscavam se cuidar, rompendo a lógica de sujeição ao que outra pessoa demanda, refazem um movimento que as desloca de si e as posiciona numa constante disposição ao/à outro/a. Assim, dificilmente podem expressar as suas demandas:

Eu preocupo comigo porque a gente também tem os filho da gente, tem marido pra gente cuidar. Eu me preocupo comigo, né, que gente tem que tá bem para atender nosso povo, nossa familia (P3, 58 anos. OF).

\section{DISCUSSÃO}

No nosso estudo, as mulheres expressam a potência da maternidade como marca maior da meia-idade e a centralidade do vínculo mãe e filhos/as como fortalecedora de subjetividades. A análise dos discursos revela uma construção identitária fortemente marcada por valores culturais que naturalizam a maternidade, sendo requisito, uma vez introjetada e vivenciada, para o bem-estar, atribuindo-se incompletude a quem não a exerceu.

Filhos/as apareceram como um dos poucos motivos de orgulho das mulheres de meia-idade participantes de nosso estudo e é, justamente, o êxito de filhos/as que dá sentido à percepção de seu próprio logro vital. Estudo chama a atenção à noção de logro como resultado de processos de socialização de homens e mulheres, em função das questões de gênero, evidenciando discursos de mulheres que assumem como próprio e tomam para si o logro individual de filhos/as ${ }^{(19)}$. Sendo assim, na saída de filhos/as de casa para seguir a vida com seus próprios projetos, alguns estudos demonstram possibilidades de mulheres vivenciarem o que se denomina de ninho vazio ${ }^{(20-21)}$.

Todavia, essa não é uma realidade das participantes desta pesquisa, uma vez que revelam em seus discursos que filhos/as continuam demandando atenção e cuidados por questões sociais e econômicas. $\mathrm{O}$ nível de independência financeira de filhos/as define limites à vida das mulheres nessa faixa etária, além de algumas sentirem a recondução ao papel materno no cuidado de netos/as. Outras não alcançam um lugar de completude de etapas com o crescimento de filhos quando condutas que se desviam das expectativas familiares e sociais, a exemplo do uso de drogas, impõem potencializar a função materna.

Por terem sua prole criada, as participantes da pesquisa mantêm o papel maternal e o estende a netos/as. Soma-se a essa condição a vulnerabilidade financeira das mulheres e de suas famílias, construindo-se a mulher como esposa abnegada.

No tocante ao vínculo com parceiros, no nosso estudo, foi destacada a violência doméstica. Mesmo diante de relacionamento em que o parceiro não contribuía com a provisão financeira e/ou nos cuidados diretos no âmbito doméstico e familiar, a manutenção de relacionamento conjugal violento é creditada à necessidade de criar filhos/as pequenos/as, perdurando anos, o que retrata o lugar da autoridade e da dependência da figura masculina na família nuclear. 
A violência doméstica é complexa, tendo em vista os vínculos que sustentam os relacionamentos. Assim, um vínculo afetivo pode não se romper com relações violentas. Para isso, contribuem questões financeiras, pressões familiares e cuidado com filhos/as, reproduzindo discursos religiosos e do senso comum como basilares para a manutenção do desequilíbrio de poder das relações e da naturalização da violência masculina contra as suas parceiras ${ }^{(22)}$.

Contudo, na meia-idade, por ocasião de filhos/as criados/ as, é possível o rompimento de relacionamentos violentos. Assim, abrem-se possibilidades para um período de maior autorealização e autonomia feminina, o que se apresenta como constatação em nosso estudo.

Pesquisa sobre conjugalidade na meia-idade evidencia que aspectos como companheirismo e tranquilidade são valorizados como fatores de satisfação conjugal. Ademais, demonstra que a temática necessita de maior aprofundamento, havendo dificuldade para encontrar estudos mais direcionados ${ }^{(23)}$.

Apesar de insatisfações acumuladas na relação conjugal, algumas participantes não vislumbram possibilidades de tomar decisões no sentido de rupturas. Nessa perspectiva, mostram-se resignadas, conseguindo subverter as normatizações sociais apenas no plano do desejo. Do ponto de vista de gênero, constroem o papel da mulher de mãe e suas vinculações subjetivas, de esposa abnegada, levando-as a se manterem presas à submissão masculina, mesmo após "cumprir os deveres da maternidade".

Nas relações familiares, as mulheres de meia-idade participantes da pesquisa cuidam e respondem a necessidades de outro/a, demonstrando o quão marcante é a socialização da mulher para o cuidado de filhos/as e para o cuidado doméstico. Assim, deslocam-se para um lugar de resignação e de pouco cuidado de si mesma, no qual filhos/as, netos/as e maridos são os significantes para anseios e cuidados de si própria.

O cuidado de si própria se dá vinculado a um ponto de vista externo, de outra pessoa, revelando uma investida avaliativa fora de seu controle, de suas necessidades e desejos. Ademais, possuem um espelho negativo, uma vez que a beleza valorizada tem como padrão o corpo jovem. Assim, perseguem uma aceitação que toma como referência o corpo jovem, o que colabora para o distanciamento da mulher da valorização e legitimação de seu próprio corpo.

Essa constatação pode ser entendida pela luz da teoria do "el yo espejo", segundo a qual o "eu" constitui uma ideia ou um conjunto de ideias extraídas da vida comunicativa que a mente abriga como se fosse sua. Parece ser integrado por três elementos centrais: a imaginação de nossa aparência para a outra pessoa; a imaginação de seu julgamento sobre essa aparência; e algum tipo de sentimento próprio, como o orgulho ou a mortificação ${ }^{(24-25)}$.

As participantes definem-se em relação ao outro, em condição muito assujeitada, de sujeito excêntrico ${ }^{(26)}$.Evidenciam que assumem em relações familiares a posição reconhecidamente feminina, à luz de gênero, "yo relacional"(26). Nesse lugar, tendem a priorizar a relação e outorgar protagonismo por sua presença e disponibilidade, convertendo-se frequentemente nas mantenedoras e cuidadoras de seus vínculos. Por outro lado, o “yo fortaleza”, posição masculina, tende a estabelecer uma série de limites sobre o que se pode esperar dele no vínculo afetivo ${ }^{(27)}$. Cabe destacar que, como as próprias autoras recordam, não significa dizer que as primeiras sejam assumidas apenas por mulheres e as segundas por homens, embora seja a situação mais frequente.

Assim, gênero apresentou-se, neste estudo, como uma lente para problematizar e descontruir leituras essencialistas e naturalizadoras do universo feminino, na conformação de experiências, de demandas e do cuidado à saúde. Permitiu olhar criticamente para suas implicações no âmbito da saúde, sinalizando a importância de transpor a lógica biomédica e vislumbrar um cuidado mais congruente com as demandas de mulheres de meia-idade e aos contextos de vida em que são geradas.

\section{CONCLUSÃO}

Os achados deste estudo evidenciam que a meia-idade feminina é marcada por concepções de feminilidade que emergem a partir da sua condição de mulher-mãe, de completa doação aos/às filhos/as e à família. Além disso, esse período de vida possibilita às mulheres olhar para trás e se ver como mãe que cuidou de filhos/as que percorreram e venceram etapas, expressando, hoje, uma posição social de missão cumprida, ainda que se apresentem novas demandas como desdobramento.

O papel de mãe e avó assumem posição central na vida daquelas que participaram da pesquisa. Assim, reafirmam-se como pessoas que tomam para si demandas de filhas/os e netos/as, tendo na resposta dada às necessidades de outra pessoa a sua valorização, o que as torna invisível para si própria. Sem projetos próprios como mulher, restringem, quase que totalmente, sua existência à função materna. Negam a si próprias a assunção do papel de sujeito de sua história, o que dificulta e até mesmo inviabiliza a identificação de demandas para o cuidado à saúde.

A pesquisa aponta para uma necessidade urgente de agregar abordagem de gênero para conhecer o contexto de vida em que se inserem as demandas das mulheres, obtendo-se subsídios para o cuidado da mulher de meia-idade. Assim, é possível considerar os entrelaçamentos biopsíquicos e sociais, questões de gênero, classe social e raça/cor na geração de demandas de saúde de mulheres de meia-idade.

A realização desta pesquisa pela adoção do método da PCA possibilitou conhecer sentidos atribuídos à meia-idade a partir da experiência de mulheres em suas relações familiares, ao tempo em que permitiu o cuidado, na medida em que experiências narradas o justificavam. Seus resultados oferecem subsídios para futuros projetos no âmbito do Ensino, da Pesquisa e da Extensão. Oferecem também contrapartida imediata às participantes favorecidas pela metodologia problematizadora adotada, além de escuta sensível de suas demandas.

Apesar dessa característica atender às pesquisas qualitativas, o tamanho da amostra pode representar uma limitação. Embora não se pretenda generalizar os resultados dos dados ou informações apresentadas, ressalta-se que a experiência das mulheres se dá em um contexto específico de vulnerabilidade econômica e social, evidenciando, assim, ser comum a um grande número de mulheres. 


\section{RESUMO}

Objetivo: Analisar sentidos atribuídos à meia-idade a partir da experiência de mulheres que a vivenciam em suas relações familiares. Método: Estudo qualitativo do tipo Pesquisa Convergente Assistencial. Gênero foi utilizado como categoria analítica, desenvolvida com treze mulheres de meia-idade de área de cobertura da Estratégia Saúde da Família em um município do sudoeste baiano, por oficinas de reflexão e entrevistas. Os dados foram analisados por meio da análise de discurso. Resultados: Expressam a relação afetiva com filhos/as e netos/as como maior marca da meia-idade em sobreposição à relação com parceiros e outros vínculos, o que inviabiliza sua singularidade e identificação de demandas para o cuidado à saúde. Conclusão: A meia-idade feminina é marcada por concepções de feminilidade que emergem a partir da sua condição de mulher-mãe, de completa doação. A pesquisa aponta para uma necessidade urgente de agregar gênero como referencial para o cuidado à mulher de meia-idade, de modo a considerar os entrelaçamentos biopsíquicos e sociais na sua experiência de vida e que delineiam demandas para o cuidado.

\section{DESCRITORES}

Pessoa de Meia-Idade; Saúde da Mulher; Relações Familiares; Gênero e Saúde; Integralidade em Saúde.

\section{RESUMEN}

Objetivo: Analizar los significados adjudicados a la mediana edad desde la experiencia de mujeres que la viven en sus relaciones familiares. Método: Se trata de un estudio cualitativo de la clase Investigación de Cuidados Convergentes en el que se utilizó el género como categoría analítica. Se llevó a cabo mediante talleres de reflexión y entrevistas entre trece mujeres de mediana edad que estaban bajo la Estrategia de Salud Familiar de un municipio del suroeste de Bahía. Los datos se analizaron a través del análisis del discurso. Resultados: Se identificó la relación afectiva con hijos/as y nietos/as como una marca importante de la mediana edad que se superpone a la relación con la pareja y otros vínculos, lo que restringe la identificación de su singularidad y las demandas para el cuidado de la salud Conclusión: La mediana edad femenina está marcada por concepciones de feminidad que surgen de su condición de mujer-madre, de entrega total. La investigación señala la necesidad urgente de añadir el género como referencia para el cuidado de las mujeres de mediana edad, con el fin de considerar el entramado biopsicosocial en su experiencia de vida que perfila las demandas del cuidado.

\section{DESCRIPTORES}

Persona de Mediana Edad; Salud de la Mujer; Relaciones Familiares; Género y Salud; Integralidad en Salud.

\section{REFERÊNCIAS}

1. Antunes PC, Silva AM. [Elements about the middle age conception, in the human aging process]. Rev Kairós [Internet]. 2013 [cited 2018 Dec 2];16(5):123-40. Portuguese. Available from: https://revistas.pucsp.br/index.php/kairos/article/view/18926

2. Nuñez DC, Méndez DN. [Social and psychological aspects of climaterium and menopause]. Medisan (Santiago De Cuba) [Internet] 2014[cited 2018 Dec 19];18(10):1409-18. Spanish. Available from: http://scielo.sld.cu/scielo.php?script=sci_arttext\&pid=S1029$30192014001000011 \& \operatorname{lng}=\mathrm{es}$

3. Vargas AC, Badilla I. [The exercise of symbolic violence in health care of middle-age women experiencing menopause: key results of a kap survey]. Rev Cienc Soc [Internet]. 2013 [cited 2018 Dec 19];140:47-72. Spanish. Available from: https://www.redalyc.org/articulo. oa?id=15329874004

4. Vargas AC, Badilla IC. ¿Protección u olvido? Salud sexual y reproductiva en la edad mediana femenina: una reflexión generacionalcontextual. Cuados Inter.c.a.mbio Centroamérica Caribe [Internet]. 2014 [cited 2018 Dec 02];11(1):135-154. Available from: https://revistas.ucr.ac.cr/index.php/intercambio/article/view/14237/13529

5. Mari FR, Alves GG, Aerts DR, Camara S. The aging process and health: what middle-aged people think of the issue. Rev Bras Geriatr Gerontol. 2016;19(1):35-44. https://doi.org/10.1590/1809-9823.2016.14122

6. Morrison LA, Brown DE, Sievert LL, Reza A, Rahberg N, Mills P, et al. Voices from the Hilo Women's Health Study: talking story about menopause. Health Care Women Int. 2014;35(5):529-48. https://doi.org/10.1080/07399332.2013.829067

7. Laskar AR; Vibha. Women's health: beyond reproductive years. Indian J Public Health. 2011;55(4):247-51. https://doi.org/10.4103/0019 $557 X .92399$

8. Kulkarni P, Savitha Rani BB, Kumar DS, Manjunath R. Burgeoning menopausal symptoms: an urgent public health concern. J Midlife Health. 2016;7(2):83-7. https://doi.org/10.4103/0976-7800.185329

9. Brasil. Ministério da Saúde; Secretaria de Atenção à Saúde. Manual de atenção à mulher no climatério/menopausa [Internet]. Brasília, DF: Ministério da Saúde; 2008 [cited 2016 Aug]. [Série A. Normas e manuais técnicos. Série Direitos sexuais e direitos reprodutivos - Cadernos, n. 9]. Available from: http://bvsms.saude.gov.br/bvs/publicacoes/manual_atencao_mulher_climaterio.pdf

10. Coelho EA, Silva CT, Oliveira JF, Almeida MS. [Integrality in women's health care: limits of practice professional]. Esc Anna Nery. 2009;13(1):154-60. Portuguese. https://doi.org/10.1590/S1414-81452009000100021

11. Garcia NK, Gonçalves R, Brigagão JI. [Primary health care actions aimed at women aged 45 to 60 years old]. Rev Eletr Enf. 2013;5(3):7119. Portuguese. https://doi.org/10.5216/ree.v15i3.18529

12. Schraiber LB, Figueiredo WS, Gomes R, Couto MT, Pinheiro TF, Machin R, et al. [Health needs and masculinities: primary health care services for men]. Cad Saude Publica. 2010;26(5):961-70. Portuguese. https://doi.org/10.1590/S0102-311X2010000500018

13. Paim L, Trentini M. A pesquisa convergente assistencial em seus atributos. Trentini M, Paim LS, Denise MGV, organizadoras. Pesquisa convergente assistencial: delineador provocador de mudanças nas práticas de saúde. 3rd ed. Porto Alegre: Moriá; 2014.

14. Melo MC. [Comprehensiveness and gender as theoretical basis for health care of pregnant adolescentes]. Rev Min Enferm. 2013;17(3):731-740. Portuguese. https://doi.org/10.5935/1415-2762.20130054

15. Fonseca RM, Amaral MA. [Reinterpretation of the potentiality of Critical-emancipative Workshops]. Rev Bras Enferm. 2012;65(5):780-7. Portuguese. https://doi.org/10.1590/S0034-71672012000500010 
16. Brito-Silva K, Bezerra AF, Tanaka OY. [Right to healthcare and comprehensiveness: a discussion on the challenges and paths towards its implementation]. Interface (Botucatu). 2012;16(40):249-260. Portuguese. http://dx.doi.org/10.1590/S1414-32832012005000014

17. Fiorin JL. Linguagem e ideologia. 8th ed. São Paulo: Ática; 2007.

18. Fiorin JL. Elementos de análise do discurso. 15th ed. São Paulo: Contexto; 2016.

19. Esteban CG, Gallego JC, Aparicio EC. Estudiar el logro profesional de las mujeres en el sistema educativo. In: Mendez AN, Pastrana MG. Mujeres en cargos de representación del sistema educativo [Internet]. Madrid: Insituto de la Mujer; 2004 [cited year Month day]. p. 87-Available from: http://www.inmujer.gob.es/areasTematicas/AreaEducacion/Estudios/docs/MujeresEducacion03.pdf

20. Sartori AC, Zilberman ML. [Revising the empty nest's syndrome concept]. Rev Psiquiatr Clin. 2009;36(3):112-21. Portuguese. https://doi.org/10.1590/S0101-60832009000300005

21. Gomes LA, Meis C, Marques V. [Menopause, empty nest and female subjectivity: an attendance report in a ward.]. Psicol. hosp. (São Paulo) [Internet]. 2014 [cited 2017 Oct 20];12(1):2-25. Portuguese. Available from: http://pepsic.bvsalud.org/scielo.php?script=sci_ arttext\&pid=S1677-74092014000100002\&lng=pt\&tlng=pt

22. Beccheri-Cortez M, Souza L. [Middle class women, gender relations and domestic violence: an exploratory study]. Rev Gerenc. Polit. Salud [Internet]. 2013 [cited 2016 August 20];12(24):34-53. Portuguese. Available from: https://revistas.javeriana.edu.co/index.php/ gerepolsal/article/view/6091

23. Azambuja JE, Jaeger FP. [Conjugality of middle-aged couples]. Disciplinarum Scientia. 2015;16(1):123-132. Portuguese. https://doi.org/10.37780/ch.v16i1.1844

24. Costa LH, Coelho EA. Ideologies of gender and sexuality: the interface between family upbringing and nursing education. Texto Contexto Enferm. 2013;22(2):485-92. https://doi.org/10.1590/S0104-07072013000200026

25. Cooley CH. El yo espejo. CIC. Cuad Inf Com [Internet]. 2005 [cited 2017 Aug 20];( 10):13-26. Available from: http://www.redalyc.org/ articulo.oa?id=93501001

26. Lauretes T. Eccentric subjects: feminist theory and historical consciousness. Femin Stud. 1990;16(1):115-150. https://doi. org/10.2307/3177959

27. Lasén A, Casado E. Mobile telephony and the remediation of couple intimacy. Fem Media Stud. 2012;12(4):550-9. https://doi.org/10.10 80/14680777.2012.741871

\section{Apoio financeiro}

Fundação de Amparo à Pesquisa do Estado da Bahia (Fapesb). Bolsa de doutorado. Coordenadoria de Aprimoramento de Pessoal de Nível Superior (Capes). Bolsa de doutorado sanduíche na Universidad Complutense de Madrid. 